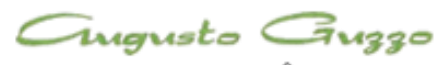

REVISTA ACADÉMICA

\title{
Revogação das Normas Jurídicas
}

\author{
Antonio Roberto Sanches Junior ${ }^{1}$ \\ Recebido em: 14/11/2014. Aprovado em: 01/12/2014. Disponibilizado em: 26/12/2014
}

\begin{abstract}
1. Doutorando em Direito na Pontifícia Universidade Católica de São Paulo (PUC-SP) - bolsista CAPES, compondo o Núcleo de Pesquisa em Direito Processual Civil. Possui Mestrado em Direito pela Universidade Católica de Santos - UNISANTOS (2008), Especialização em Direito Civil pela Universidade Paulista (2005) e graduação em Direito pela Universidade Paulista (2004). Advogado Inscrito na Ordem dos Advogados do Brasil Seccional São Paulo desde 2004, atuando no contencioso Cível e Empresarial. Além de Advogado é professor de Direito Processual Civil na Faculdade de Direito da Universidade São Judas Tadeu - USJT; Direito Processual Civil, Civil, Empresarial e do Consumidor na Faculdade de Direito da Universidade Nove de Julho UNINOVE; Direito Processual Civil nos cursos de Pós-Graduação Lato Sensu das Faculdades Metropolitanas Unidas FMU; e Direito Processual CIvil, Empresarial e do Consumidor nos cursos de Pós-Graduação Lato Sensu e MBA da Universidade Municipal de São Caetano do Sul - USCS / IMES; professor licenciado na Sociedade Acadêmica Amparense Registro-SP. Tem experiência na área de Direito, com ênfase em Direito Processual e Civil.
\end{abstract}

\section{Resumo}

Este trabalho se propõe a estudar o fenômeno jurídico da revogação das normas jurídicas. Parte da premissa que as duas expressões centrais tratadas ("revogação" e "normas jurídicas") são expressões equívocas, vale dizer, polissêmicas. É dividido em dois capítulos. O primeiro capítulo se presta à conceituação de norma jurídica, não tendo a intenção de discorrer sobre todas as fontes do direito, mas apenas alocar o termo "norma jurídica" dentro dos limites necessários para o desenvolvimento do raciocínio que se pretende fazer, separando "norma jurídica" entendida como sinônimo de texto normativo, também chamado de enunciado prescritivo, do termo "norma jurídica" entendido como o produto da interpretação desse texto normativo. O segundo capítulo se presta ao estudo da revogação enquanto fenômeno jurídico, em que se estuda a natureza jurídica da revogação, bem como revogação sob os prismas dos dois sentidos dados à expressão "norma jurídica" desenvolvidos no primeiro capítulo.

Palavras-chave: revogação, norma jurídica, texto normativo.

\begin{abstract}
This paper aims to study the legal phenomenon of withdrawal of legal rules. Part of the premise that the two key expressions treated ("withdrawal" and "rules of law") are equivocal expressions, that is, polysemic. It is divided into two chapters. The first chapter provides the concept of rule of law, not intending to discuss all the sources of law, but only allocate the term "rule of law" within the limits necessary for the development of reasoning that they intend to do, separating "standard legal "understood as synonymous with normative text, also called prescriptive statement, the term" rule of law "understood as the product of the interpretation of this regulatory text. The second chapter provides the study of withdrawal as a legal phenomenon, when investigating the legal nature of withdrawal and revocation under the prism of the two meanings given to the term "rule of law" developed in the first chapter.
\end{abstract}

Keywords: revocation, legal standard, normative text 


\section{Introdução}

A polissemia é fenômeno tão presente no direito, quanto prejudicial à compreensão das expressões cunhadas durante $\mathrm{O}$ desenvolvimento do direito como ciência e como sistema. Em que pese tal constatação, a polissemia é inevitável quando um objeto - o direito - é construído, inexoravelmente, por expressões lingüísticas, como o caso do direito.

Essa prejudicialidade se potencializa quando conjugadas as duas expressões que guardam grande espectro de polissemia. É o que se verifica quanto se estudam os efeitos e as consequências de um instituto jurídico polissêmico - revogação - em outro instituto polissêmico - norma jurídica.

A expressão "norma jurídica" pode ser tomada sob vários aspectos, dentre os quais, podemos destacar: i) texto normativo; ii) texto normativo que contenha regulação direta de condutas humanas, vale dizer, relações intersubjetivas; iii) texto normativo que contenha regulação direta de condutas humanas, vale dizer, relações intersubjetivas e estabeleça sanções para o seu descumprimento; iv) produto da interpretação dos textos normativos.

A adoção de cada um dos conceitos de "norma jurídica" afeta a concepção sob a qual o interprete aborda todo o fenômeno jurídico e sua dinâmica na regulação da vida em sociedade.

Um desses aspectos é a própria mutação desse ordenamento jurídico, que se dá, dentre outros, por meio da "revogação", que também pode ser tomada pelo intérprete como: i) retirada de existência de uma norma jurídica; ii) retirada de validade da norma jurídica; iii) retirada de eficácia de uma norma jurídica. A cada uma dessas retiradas corresponde, também, uma consequência diferente no que diz respeito à regulação da vida em sociedade.

Como se não bastassem as diferentes conseqüências que podem ter a adoção de uma posição com relação a quais efeitos a revogação provoca, deve-se também perquirir quando ela ocorre, o que impende o estudo conjugado dos institutos jurídicos: i) norma jurídica; e ii) revogação.

Em se adotando norma jurídica como sinônimo de texto normativo, se estará diante da revogação como ato que atinge esse texto normativo, em sua existência, validade ou eficácia.

Ainda assim, deverá ser ponderado se essa revogação pode ocorrer somente pela previsão, por outro texto normativo de igual superior hierarquia ou pode decorrer de conclusões tidas por um dado interprete do direito acerca do afastamento de texto anterior como efeito de disposição de texto normativo posterior que lhe seja contrário, caso em que também demandará a investigação de se, quando e em que medida esse texto normativo posterior é contrário ao texto normativo anterior, investigação essa que passará pelos critérios de interpretação do direito e pré-compreensões do intérprete, variáveis subjetivas.

Por outro lado, em se adotando norma jurídica como produto da interpretação do texto normativo, as conseqüências da revogação mudam de patamar, na medida em que a própria constatação do afastamento de uma norma jurídica decorrerá da construção do significado de uma norma jurídica a partir do conjunto de textos normativos existentes e seus significados.

Sem a pretensão de esgotar o tema, esse estudo se destina a suscitar reflexões acerca dos institutos "norma jurídica" e "revogação", bem como da relação entre um e outro. 


\section{Norma Jurídica}

\subsection{Conceito}

Para fins de posicionamento metodológico, não somente para a digressão que ora se faz, mas para a abordagem do sistema jurídico como um todo, importante destacar como conceituaremos (e conceituamos) norma jurídica.

O problema fundamental é saber o que é norma jurídica, vez que se irá discutir a respeito da revogação - ou impossibilidade de - desse objeto.

Verifique-se que a problemática a respeito de como (e se é possível) chegar a um conceito de norma jurídica é tratada pelos mais renomados estudiosos do Direito.

Aurora Tomazini Carvalho ${ }^{1}$, em sua tese de doutoramento pela PUC-SP, expõe textualmente o problema:

Ponto crucial de qualquer teoria sobre a norma jurídica e saber: 'que é uma norma jurídica?’. E o que podemos dizer é que, antes e qualquer coisa 'norma jurídica', é uma expressão lingüística, que como tantas outras não escapa do vício da ambigüidade, podendo ser utilizada nas mais diversas acepções (CARVALHO:2009:213).

Tomazini ${ }^{2}$ esclarece a utilização variada da expressão "norma jurídica" como significando coisas diferentes, tal como observa na obra de Gregório Robles, que, segundo a autora, "utiliza-se da expressão fazendo referência, primordialmente, às significações construídas pelo interprete a partir dos textos do direito positivo".

${ }^{1}$ Carvalho, Aurora Tomazini. Teoria geral do direito: (o constructivismo logico-semântico). Tese. Doutorado em Direito. São Paulo: Pontifícia Universidade Católica, 2009, p. 213. Disponível em http://www.sapientia.pucsp.br/tde_busca/arquivo .php?codArquivo=9427 acesso em 27/06/2014.
Contudo, lembra que o mesmo autor, em outras passagens, "também designa, com a mesma expressão, enunciados jurídicos". Essas duas formas diferentes da utilização da expressão "norma jurídica" lembra, ainda, ocorrem na obra de Ricardo Guastini.

Mantendo a profundidade e a coerência de sua pesquisa, Tomazini ${ }^{3}$ separa os planos de abordagem do fenômeno jurídico para concluir que:

considerando a expressão 'norma jurídica', quando utilizada para apontar indiscriminadamente as unidades do sistema jurídico, pode denotar (i) enunciados do direito positivo; (ii) a significação deles construída; oi (iii) a significação deonticamente estruturada, dependendo do plano em que o intérprete trabalha.

Para reforço de convicção, lembra a abordagem do Professor Paulo de Barros Carvalho, no sentido de separar as expressões em:

(i) "normas jurídicas em sentido amplo" para designar tanto as frases enquanto suporte físico do direito posto, ou os textos de lei, quanto os conteúdos significativos isolados destas; e (ii) "normas jurídicas em sentido estrito" para aludir à composição articulada das significações, construídas a partir dos enunciados do direito positivo

De imediato é possível constatar que o texto legal não se confunde com norma jurídica. Aquele é, no máximo, espécie desta. Dizemos "no máximo" porque há aqueles que entendem os textos normativos, vale

\footnotetext{
${ }^{2}$ CARVALHO, Aurora Tomazini. Teoria geral do direito: (o constructivismo logico-semântico). Tese. Doutorado em Direito. São Paulo: Pontifícia Universidade Católica, 2009, p.214. Disponível em http://www.sapientia.pucsp.br/tde_busca/arquivo .php?codArquivo $=9427$ acesso em 27/06/2014.

${ }^{3}$ Idem. Ibidem
} 
dizer, enunciados prescritivos, como normas jurídicas. Para estes, as normas jurídicas seriam, propriamente, os enunciados prescritivos (que aqui também chamamos de textos normativos) textualmente inseridos no produto da atividade do Poder Legislativo. Para outros, contudo, tais enunciados fazem parte do conjunto de normas que compõem o ordenamento jurídico, não se encerrando, todavia, neles.

Hans Kelsen ${ }^{4}$, discorrendo sobre o objeto da ciência jurídica, salienta ser, tal objeto, a norma jurídica, momento em que aduz:

A produção das normas jurídicas gerais, isto é, o processo legislativo, é regulado pela Constituição, e as leis formais ou processuais, por seu turno, tomam à sua conta regular a aplicação das leis materiais pelos tribunais e autoridades administrativas. Por isso, os atos de produção e de aplicação (que, como veremos, também é ela própria produção) do Direito (...) (grifo nosso).

Como é possível depreender do trecho transcrito, Kelsen atribui ao processo legislativo a produção das normas jurídicas gerais. Como é cediço, o processo legislativo, desempenhado pelo Poder Legislativo, e constitucionalmente regulado - a redundância é necessária para deixar claro do que se está a falar - tem como produto o texto de lei - aqui empregada a expressão no mais amplo sentido, vale dizer, Constituição, leis e outros instrumentos legislativos emanados desse Poder estatal.

Nesse sentido, resta demonstrada a similitude, para Kelsen, entre as expressões norma jurídica e texto produzido pelo Poder Legislativo.

É certo, Kelsen também admite que o conceito de norma jurídica não se esgota nesse texto produzido pelo Legislativo, como deixa claro ao pontuar que os atos de aplicação também são, em última análise, atos de produção de norma jurídica.

Nesse sentido a nota de fim n.4 inserida no capítulo 3 da obra de Hans Kelsen": "na terminologia tradicional da jurisprudência alemã as expressões Rechtsnorm (norma jurídica) e Rechsstatz (proposição jurídica) são usadas como sinônimas".

Como visto, ao mesmo tempo em que Kelsen admite a atividade de subsunção de um determinado fato ao texto legal como criação de norma jurídica - individual e concreta -, coloca esse mesmo texto como sendo norma jurídica.

Franco Montoro ${ }^{6}$, ao discorrer sobre as fontes do direito, coloca as decisões judiciais entre tais fontes. Nessa medida, ao se entender que as decisões judiciais são fontes do direito, pode-se-lhes atribuir o status de norma jurídica, eis que instrumento de regulação de condutas humanas, o que fica claro com a seguinte lição: "A atividade jurisdicional ou judicante leva, por isso, quase necessariamente à formulação explícita de regras (...)". (grifamos). Contudo, mais à frente Franco Montoro salienta que "a lei é uma norma 'geral' ou comum". Tal afirmação demonstra a lição, para o autor, no sentido de ser, a lei, norma, embora - como acima dito - esse mesmo autor reconheça que não é a única modalidade de norma.

\footnotetext{
${ }^{6}$ Montoro, André F. Introdução à ciência do direito. 25.ed., São Paulo: Revista dos Tribunais, 1999, p. 325-7.
}

\footnotetext{
${ }^{4}$ Kelsen, H. Teoria pura do direito. [trad. João Baptista Machado] 6.ed. São Paulo: Martins Fontes, 1998:79 e ss.

${ }^{5}$ Kelsen, H. Teoria pura do direito. [trad. João Baptista Machado] 6.ed. São Paulo: Martins Fontes, 1998, p. 80.
} 
Miguel Reale ${ }^{7}$ conceitua norma jurídica como "uma estrutura proposicional enunciativa de uma forma de organização ou de conduta, que deve ser seguida de maneira objetiva e obrigatória". Por "estrutura proposicional enunciativa" podemos entender o comando prescritivo textualmente estabelecido. É certo que não se depreende das lições de REALE que norma jurídica se reduza a textos prescritivos, mas, tão certo quanto, é o fato de assumir que tais enunciados são normas jurídicas. Ao estudar a lei como fonte do direito, Vicente Ráo ${ }^{8}$ pondera que, em sentido próprio e formal, "é a lei a norma geral de direito formulada e promulgada, por modo autêntico, pelo órgão competente, da autoridade soberana (...)". Como se verifica, RÁO também coloca a lei como norma jurídica.

Tercio Sampaio Ferraz Junior ${ }^{9}$ destaca que, atualmente, dada a complexidade das sociedades, se verifica uma tendência de positivação do direito, antes disposto, em sua maioria, por normas morais, consuetudinárias etc., fenômeno que denomina como "constitucionalismo" e "legalismo" que, salienta, positivam "por procedimentos regulados, o direito natural, a moral e o costume". Como se depreende da lição de Ferraz Junior, o estabelecimento de enunciados textualmente dispostos é tendência que se verifica hodiernamente, ante as características da sociedade, tais como a complexidade e, em nosso ver, a massificação.

Contudo, Ferraz Junior ${ }^{10}$ pondera, ao conceituar norma jurídica do ponto de vista estrutural, que "são expressões de expectativas contrafáticas, institucionalizadas e de cunho generalizável. Compõe-se,

\footnotetext{
${ }^{7}$ Reale, Miguel. Lições preliminares de direito. 25.ed., São Paulo: Saraiva, 2000, p. 95

${ }^{8}$ Ráo, V. O direito e a vida dos direitos. 5.ed. anotada e atualizada por Ovídio Rocha Barros Sandoval, São Paulo: RT, 1999, p. 281.
}

destarte, de mensagens, emissores e agentes receptores", ${ }^{11}$ pelo que é possível verificar que, em seu entender a norma jurídica não se encerra no enunciado prescritivo, mas este faz parte daquela. Continuando em sua lição, salienta que "as mensagens ocorrem em dois níveis: o da relação ou cometimento e o do conteúdo ou relato", para ponderar que "o relato ou conteúdo normativo é constituído por decisões de ações, de suas condições e suas consequências".

\subsection{Espécies}

Como visto, a maioria da doutrina jurídica equipara lei, vale dizer, texto legal (normativo, enunciado ou outro nome que se dê) a norma jurídica. Em que pese tal afirmação não se encontre textualmente estabelecida pelos autores, é de clara depreensão, na medida em que durante todo o discurso se refere à lei como norma jurídica e a norma jurídica como lei.

A distinção que se pretende fazer para fins do raciocínio a ser desenvolvido - o que justifica o presente item (espécies de norma jurídica) - é entre norma como enunciado textual (estabelecido em quaisquer instrumentos, tais como: lei, princípio positivado, súmula etc.) e norma como produto obtido a partir da interpretação desse mesmo enunciado textual. É a partir dessa diferenciação que se entendem como fenômenos distintos texto e norma jurídica.

\footnotetext{
${ }^{9}$ Ferraz Jr, T S. Introdução ao estudo do direito técnica, decisão, dominação. São Paulo: Atlas, 1988:111

10 idem

11 idem
} 
Para Paulo De Barros Carvalho ${ }^{12}$ resta clara a polissemia - ambiguidade, em suas palavras - da expressão norma jurídica.

A despeito disso, porém, interessa manter o secular modo de distinguir, empregando "normas jurídicas em sentido amplo" para aludir aos conteúdos significativos das frases do direito posto, vale dizer, aos enunciados prescritivos, não enquanto manifestações empíricas do ordenamento, mas como significações que seriam construídas pelo intérprete.

Com a percuciência que lhe é peculiar EROS GRAU 13 ensina que "da interpretação do texto surge a norma” e não o contrário. É dizer: texto não se confunde com norma, embora esta seja construída a partir daquele. Essa reflexão é desenvolvida mais profundamente, por ocasião de seu "Ensaio e discurso sobre a interpretação/aplicação do direito", quando Eros Grau ${ }^{14}$ pontifica:

Antes disso, no entanto, um aspecto importantíssimo deve ser explicitado, atinente ao equivoco reiteradamente consumado pelos que supõem que se interpretam normas. $\mathrm{O}$ que em verdade se interpreta são os textos normativos. Da interpretação dos textos resultam as normas. Texto e norma não se identificam. A norma é a interpretação do texto normativo. A interpretação é, portanto, atividade que se presta a transformar textos - disposições, preceitos, enunciados - em normas. Daí, como as normas resultam da interpretação, o ordenamento, no seu valor histórico-concreto, é um conjunto de interpretações, isto é, um

\footnotetext{
${ }^{12}$ Carvalho, Paulo de Barros. Direito Tributário, Linguagem e Método. São Paulo: Noeses, 2013, p. 128

${ }^{13} \mathrm{Grau}$, Eros Roberto. O direito posto e o direito pressuposto. 6.ed. São Paulo: Malheiros, 2005, p. 207

${ }^{14} \mathrm{Grau}$, Eros Roberto. Ensaio e discurso sobre a interpretação/aplicação do direito. 5.ed. São Paulo: Malheiros, 2009, p. 27
}

conjunto de normas. O conjunto dos textos - disposições, enunciados - é apenas ordenamento em potencia, um conjunto de possibilidades de interpretação, um conjunto de normas potenciais [Zagrebelski]. O significado (isto é, a norma) é o resultado da tarefa interpretativa. Vale dizer: o significado da norma é produzido pelo intérprete. Por isso dizemos que as disposições, os enunciados, os textos, nada dizem. Eles dizem o que os intérpretes dizem que eles dizem [Ruiz e Cárcova]

Ainda Grau, por ocasião de seu voto no julgamento da ADPF 153-DF ${ }^{15}$ assim ponderou: "Hoje temos como assentado o pensamento que distingue texto normativo e norma jurídica, a dimensão textual e a dimensão normativa do fenômeno jurídico. O intérprete produz a norma a partir dos textos e da realidade". José Joaquim Gomes Canotilho $^{16}$ também diferencia texto normativo de norma. Para o professor português “' O recurso ao 'texto' para se averiguar o conteúdo semântico da norma constitucional não significa a identificação entre texto e norma". Nessa medida, pontuamos as duas espécies de normas jurídicas sobre as quais discorreremos, no que diz respeito à revogação, quais sejam: i) texto normativo - comumente tratado como sinônimo de norma jurídica -; e ii) norma jurídica que decorre - é produto - do resultado da interpretação do texto normativo.

Essa distinção se torna imperiosa, pois, quanto à segunda espécie a revogação, tal qual será tratada no presente estudo, se confunde com a atividade interpretativa, na medida em

\footnotetext{
${ }^{15}$ Supremo Tribunal Federal. Tribunal Pleno. Arguição de Descumprimento de Preceito Fundamental n. 153/DF. Relator Ministro Eros Grau. j. 29/04/2010. DJe-145. divulgado em 05-082010, publicado em 06-08-2010. Ement Vol-0240901 PP-00001. RTJ VOL-00216- PP-00011. ${ }^{16}$ Canotilho, J.J. Gomes. Direito Constitucional e teoria da constituição.7.ed. 13.reimp. Coimbra: Almedina, 2003, p. 1218
} 
que, nesse caso, a norma nasce da atividade interpretativa e, em consequência, pode deixar de existir com a mesma atividade interpretativa. Tal fenômeno - a interpretação como mecanismo de revogação de norma jurídica - não é novidade em sede de análise da revogação, vez que em se tratando da chamada revogação tácita, o estabelecimento do que está ou não revogado pela lei posterior decorre da atividade de interpretação dessa mesma lei posterior.

\section{Revogação}

\subsection{Conceito}

A polissemia seja da expressão norma jurídica, seja da expressão revogação, é problema de áspero enfrentamento. Isso se dá porque a expressão norma jurídica é, em si, termo equívoco, vale dizer, polissêmico como já visto. Contudo, estabelecidas as premissas - sem a pretensão de que sejam definitivas, mas tão somente para delimitarmos a abordagem que pretendemos - conseguimos estabelecer a pedra fundante para a construção de nosso raciocínio. Ocorre, todavia, que, vencida a polissemia da primeira expressão - norma jurídica - nos deparamos com a polissemia, talvez mais grave, porque mais abrangente - da segunda expressão de nosso estudo: revogação. E o estudo desse instituto jurídico é tão mais profundo quanto mais se diversificam os conceitos de norma jurídica.

Tarek Moyses Moussallem ${ }^{17}$ relata as várias acepções que revogação pode assumir:

(1) ato; (2) efeito de tal ato e suas variantes; (2a) expulsão da norma do sistema (perda da validade); (2b) perda da vigência; (2c) perda da eficácia; (2d) perda da possibilidade de ser aplicada; (3) fato jurídico da repristinação (também como efeito do ato

17 Moussallem, Tarek Moyses. Revogação em matéria tributária. São Paulo: Noeses, 2007, p. 181 de revogação); (4) ab-rogação; (5) derrogação; (6) anulação; (7) conflito de normas; (8) nulidade; (9) negação; (10) dessuetude; (11) ato jurídico unilateral (revogação de mandato); (12) ato administrativo discricionário (no direito administrativo); (13) expressão descritiva como "a norma A foi revogada pela norma B"

Não serão estudadas todas as acepções do termo revogação, eis que esse não é o escopo do presente trabalho. Contudo, abordaremos as peculiaridades da revogação atinentes à conclusão que se pretende chegar, qual seja, se ela existe nas modalidades tácita e expressa, bem como se é um fenômeno atinente à norma jurídica ou ao texto normativo.

\subsection{Características}

\subsubsection{Perda Imediata de "Validade"}

Moussallem $^{18}$, com apoio em Kelsen, relata a imediata perda de validade do enunciado prescritivo revogador, eis que, uma vez revogado o enunciado anterior, por expressa disposição do enunciado posterior a isso criado, há a completa perda de efeitos desse enunciado, na medida em que ele não se presta a regular nenhuma conduta, mas apenas a retirar do conjunto de enunciados prescritivos um determinado texto, ou seja, por não se prestar a regular conduta humana, não faz mais sentido a existência/validade do enunciado revogador após ter exaurido sua finalidade.

Essa característica é verdadeiramente presente em enunciados prescritivos exclusivamente destinados à revogação de outros enunciados, na medida em que, nos termos do $\int 3^{\circ}$, do art., $2^{\circ}$, da Lei de Introdução às Normas do Direito Brasileiro, em se tratando de revogação não há

\footnotetext{
18 Moussallem, Tarek Moyses. Revogação em matéria tributária. São Paulo: Noeses, 2007, p. 185.
} 
repristinação - nos referimos dessa maneira por não olvidar acerca da repristinação de lei quando do controle da constitucionalidade de lei, quando o texto que revogou o anterior é declarado inconstitucional, caso em que o texto revogado volta a ter eficácia -, o que tem como consequência a impossibilidade de retorno, ao ordenamento jurídico, do enunciado prescritivo revogado, pelo que se reitera, perderá o enunciado prescritivo revogador, em absoluto, a validade com o esgotamento dos efeitos jurídicos que dele poderiam advir.

Apenas, ressalte-se, temos dúvidas acerca de ser a validade o que é atingido pelo esgotamento dos efeitos de um enunciado prescritivo revogador. Isso se dá porque a retirada de um enunciado prescritivo, pelo esgotamento dos efeitos que dele poderiam advir, a priori, não atinge sua validade - tida como relação de compatibilidade vertical, vale dizer, o respeito ao ordenamento jurídico que lhe é hierarquicamente superior e dá suporte de validade.

Em verdade, data venia, temos que o esgotamento dos efeitos de determinado enunciado prescritivo exclusivamente revogador atinja sua eficácia, vale dizer, a produção de efeitos em uma dada situação jurídica específica - embora não em um caso concreto, ou seja, em uma relação intersubjetiva, mas sim situação jurídica específica: a existência, a partir daquele momento, de um enunciado prescritivo.

Não entendemos eficácia como efeitos em um dado caso concreto, mas em uma relação jurídica especifica, podendo ser um caso concreto ou uma relação jurídica em abstrato, como a permanência de outro enunciado prescritivo. Dessa maneira, revogado o texto anterior pelo novo, o que existe é a perda de eficácia do enunciado revogador, por desnecessidade, mas não sua invalidade, que seria atingida se não houvesse, por parte do enunciado revogador, relação de compatibilidade vertical com o sistema em que está inserido, caso em que haveria outra consequência, qual seja, o reconhecimento dessa invalidade, com a respectiva declaração de invalidade e retorno dos efeitos do enunciado revogado.

Isso é sobrelevado quando compulsado o regime jurídico do controle concentrado de constitucionalidade em que, uma vez reconhecida a inconstitucionalidade de texto normativo revogador, o texto normativo revogado volta a ser eficaz.

O Supremo Tribunal Federal ${ }^{19}$ já se manifestou acerca do efeito repristinatório do controle concentrado de constitucionalidade. Nesses casos, entende o STF, em sendo declarada inconstitucional a lei revogadora, volta à eficácia a lei revogada.

Considerando que o controle concentrado de constitucionalidade se presta à verificação de validade - entendida como relação de compatibilidade vertical - de uma lei, resta claro que nesse caso, sim, seria atingida a validade do enunciado revogador, o que não ocorre com a perda de eficácia decorrente da desnecessidade caracterizada pelo exaurimento dos efeitos de um enunciado exclusivamente revogador.

\subsubsection{Necessidade de previsão (inexistência de revogação tácita)}

O fenômeno amplamente conhecido como revogação tácita decorre do disposto na parte final do $\int 1^{\circ}$, do art. $2^{\circ}$, da Lei de Introdução às Normas do Direito Brasileiro - LINDB: "A lei posterior revoga a anterior quando (...) seja com ela incompatível ou quando regule inteiramente a matéria de que tratava a lei anterior".
${ }^{19}$ STF - Informativo n. 224. disponível em: http://www.stf.jus.br//arquivo/informativo/docu mento/informativo224.htm . acesso em 25/06/2014

SANCHES JUNIOR, A.R.: Revogação das Normas Jurídicas 
Carlos Maximiliano ${ }^{20}$, já no início do século passado criticava esse instituto, defendendo a necessidade de revogação somente na modalidade expressa e que não fosse mais utilizada a expressão "revogam-se as disposições em contrário", que o autor classificou como "uso inútil; superfetação, desperdício de palavras, desnecessário acréscimo".

Em 1998, obedecendo a mandamento constitucional estampado no parágrafo único do art. 59, que estabelece a necessidade de Lei Complementar para regular o processo legislativo, foi editada a Lei Complementar n. 95, cujo art. $9^{\circ}$ estabelece a necessidade de cláusula expressa de revogação, ${ }^{21}$ sendo seguida no mesmo exato sentido, pelo art. 21, do Decreto n. 4176/02, que a regulamenta.

Em sendo cogitada eventual antinomia entre a LINDB e a LC 95/98, o problema se dissolve de pronto, a uma porque a Constituição Federal estabelece a necessidade de lei complementar para regular o processo legislativo, em complementação às disposições constitucionais, de maneira a se considerarem não recepcionados pela Constituição os dispositivos da LINDB que tratam de elaboração de textos normativos; a duas porque a Lei de Introdução às Normas do Direto Brasileiro não se presta a regular a elaboração dos enunciados prescritivos, vale dizer, texto de lei, mas estabelece institutos jurídicos dos mais variados segmentos, exceto elaboração de leis.

São exemplos de institutos tipicamente regulados pela LINDB: presunção juris et de jure de conhecimento da

${ }^{20}$ MAXIMILIANO, Carlos. Hermeneutica e aplicação do direito. 18.ed. Rio de Janeiro: Forense, 2000, p. 357.

${ }^{21}$ Art. 9o. A cláusula de revogação deverá enumerar, expressamente, as leis ou disposições legais revogadas lei (art. $3^{\circ}$ ), determinação de qual ordenamento se aplica a determinados atos jurídicos $\left(\operatorname{art} .7^{\circ}\right)$, ônus e meios de prova de fatos ocorridos em outro país (art. 13).

Maria Helena Diniz ${ }^{22}$, com apoio em Wilson de Campos Batalha, salienta a função da LINDB asseverando que tal diploma normativo: "disciplina as próprias normas jurídicas, assinalando-lhes a maneira de aplicação e entendimento", pelo que se depreende que não é concebida para regular o processo de elaboração (e revogação) das leis, mas sua aplicação.

Confira-se, em outra oportunidade, ensinamento de Diniz ${ }^{23}$ no sentido de que a lei de introdução tem como função reger as normas, "uma vez que indica como interpretá-las ou aplicá-las". Como se não bastasse, a redação original do art. $9^{\circ}$ da LC 95/98, era: “Quando necessária a cláusula de revogação, esta deverá indicar expressamente as leis ou disposições legais revogadas". Com o advento da LC 107/01 passou a ser: "A cláusula de revogação deverá enumerar, expressamente, as leis ou disposições legais revogadas".

A exposição de motivos do PLC 23$\mathrm{B} / 1999^{24}$, que culminou com sua promulgação como Lei Complementar 107, não alterava o art. $9^{\circ}$ da LC 95/98. A alteração do art. $9^{\circ}$ foi inserida como substitutivo apresentado por ocasião do parecer da Comissão de Constituição e Justiça e de Redação, cujo relatório, adotado como exposição de motivos do substitutivo, nada falou a respeito da alteração do texto do art. $9^{\circ}$, exceto “a lei complementar está a merecer

\footnotetext{
22 Diniz, M. H, Curso de direito civil brasileiro. v.1., Teoria geral do direito civil, 28.ed. São Paulo: Saraiva, 2011, p. 73

${ }^{23}$ Diniz, M H, Lei de introdução ao código civil brasileiro interpretada. 7.ed. São Paulo: Saraiva, 2001, p. 4.

24 Diário da Câmara dos Deputados, 09 de maio de 2000, pp. 22.799 e ss.
} 
pequenos reparos de redação, para afastar interpretações divergentes de menor relevância aqui e ali suscitadas" ${ }^{25}$.

A ausência de indicação, por parte daqueles que propuseram a alteração textual, nos permite inferir, antes de suas intenções, suas conseqüências no ordenamento jurídico. Nesse sentido, verifique-se que a redação anterior usava a locução "quando necessária", não repetida no dispositivo após a alteração.

A existência da locução "quando necessária" permitia inferir a necessidade, somente em alguns casos, da cláusula de revogação. Essa necessidade episódica contrastava com a parte final do dispositivo, que exigia, sempre, a cláusula expressa de revogação.

É certo que a locução "quando necessária”, antes de significar a necessidade episódica da cláusula de revogação, se referia aos casos em que é necessária a cláusula de revogação, quais sejam, os casos em que lei anterior disponha sobre o mesmo assunto.

Ocorre que nesse caso, ante a necessidade existência expressa de cláusula de revogação, despicienda se mostrava a locução "quando necessária", porque sempre é necessária a cláusula, exceto quando não houver texto dispondo sobre o mesmo assunto, caso em que nem se cogita em clausula de revogação.

Confira-se: se é exigida cláusula de revogação, em havendo norma anterior que o novel legislador pretenda revogar, deverá dispor expressamente. Nesse sentido, desnecessária a locução "quando necessária", da redação anterior do art. 9 da LC 95/98, eis que, em havendo lei anterior e sendo a vontade do legislador sua revogação deverá dispor texto nesse sentido. Pela necessidade

${ }^{25}$ Diário da Câmara dos Deputados, 09 de maio de 2000, p. 22.806

${ }^{26}$ Moussallem, Tarek Moyses. Revogação em matéria tributária. São Paulo: Noeses, 2007, p. 186 de texto, para que se tenha a revogação de outro texto, as lições de Moussallem: "percebe-se, de plano, que a revogação é uma função específica de enunciados prescritivos pertencentes ao sistema do direito positivo. Isso reforça a premissa: sem enunciação, que lance enunciados revogatórios no sistema, não há que falar em revogação". ${ }^{26}$

Também como apoio em Paulo de Barros Carvalho, Moussallem, ${ }^{27}$ salienta que "não á dúvidas de que a revogação encontra sua melhor manifestação no plano dos enunciados prescritivos e sua forma canônica será sempre 'Revoga-se o enunciado...". Dessa maneira, importa deduzir que a revogação tácita, está mais para atividade interpretativa, do que na seara da revogação da lei, na medida em que definir se, quando e em que medida a lei nova dispôs sobre o mesmo assunto já regulado por lei anterior é atividade interpretativa, vinculada às précompreensões do intérprete, o que tem como consequência a possibilidade de entendimentos diversos a respeito $\mathrm{da}$ revogação, ou não, de um texto de lei.

\subsubsection{Não Regulação de condutas humanas}

A revogação de enunciados prescritivos por outros exclusivamente revogadores é medida não destinada, a priori, a regular a conduta humana, eis que o comando trazido pelo texto se presta apenas a revogar outro texto. Nesse sentido Moussallem ${ }^{28}$ salienta que "afigura-se impossível à revogação existir como norma jurídica em sentido estrito (na estrutura lógico-sintática do condicional), haja vista que não se refere à conduta humana" e, lembrando a teoria de Kelsen, ressalta que "o functor não-dever-ser (nonought) é incompatível com o nexo imputacional".

\footnotetext{
27 idem

28 idem
} 
Indo além, Moussallem ${ }^{29}$, apoiado em Alchourrón e Bulygin entende que os enunciados revogatórios nem se incluem na categoria de normas, mas sim de enunciados não normativos, no que discorda de Kelsen, para quem são sim normas, mas de uma categoria diferente, justamente pelo fato de não se dirigirem diretamente (no entendimento de Kelsen) - a redundância é propositada e será demonstrada adiante - a condutas humanas.

Moussallem $^{30}$ discorda, contudo, da posição de Kelsen segundo a qual o enunciado revogador não se presta a regular conduta humana. Par ao autor, Kelsen não atentou para duas circunstâncias, quais sejam: i) o enunciado revogador estipula "o dever ser da revogação"; e ii) "a revogação cria um novo sistema normativo".

Sobre a mesma questão, em se tratando de enunciados prescritivos constitucionais mas o quanto aqui desenvolvido vale, claramente, para o ordenamento infraconstitucional -, José Afonso da Silva ${ }^{31}$, se debruça, para discutir acerca da aplicabilidade das normas constitucionais que classifica como "de eficácia limitada" 32 .

Lembra Afonso da Silva, ${ }^{33}$ que o desenvolvimento do estudo das normas jurídicas a partir da perspectiva de sua aplicabilidade se deu com doutrina e jurisprudência norte-americanas, quando houve a divisão em self-executing e not selfexecuting, para diferenciar estas como sendo não passiveis de execução/aplicação imediata e, aquelas, dotadas de tal efeito, momento em

\footnotetext{
${ }^{29}$ Moussallem, Tarek Moyses. Revogação em matéria tributária. São Paulo: Noeses, 2007, p. 188. ${ }^{30}$ Moussallem, Tarek Moyses. Revogação em matéria tributária. São Paulo: Noeses, 2007, p. 189. ${ }^{31}$ Da Silva, José A. Aplicabilidade das normas constitucionais, 7.ed. 2t. São Paulo: Malheiros, 2008:117 e ss.

${ }^{32}$ Não faremos digressões sobre os enunciados prescritivos constitucionais classificados por JOÉ
}

que informa a desatualização dessa dicotomia, mais atinente ao período anterior às grandes guerras. Para Afonso da Silva:

A classificação pura e simples das normas constitucionais em autoaplicáveis e não auto-aplicáveis não corresponde, com efeito, à realidade das coisas e às exigências da ciência jurídica, nem às necessidades práticas de aplicação das constituições, pois sugere a existência, nestas, de normas ineficazes e destituídas de imperatividade .34

Aprofundando o estudo das normas de eficácia limitada, Afonso da Silva ${ }^{35}$ destaca existirem várias espécies de normas dessa natureza, que podem ser reunidas em dois grupos: “(a) declaratórias de princípios institutivos; (b) declaratórias de princípio programático", mas conclui que "cada norma constitucional é sempre executável por si mesma até onde possa, até onde seja suscetível de execução". Dessa reflexão se depreende a efetiva eficácia/aplicabilidade de todo e qualquer texto normativo. Toda norma se presta à regulação de condutas humanas, inclusive os enunciados prescritivos revogadores, na medida em que se prestam a alterar o ordenamento jurídico criando um novo sistema jurídico, nas palavras de Moussallem -, seja para permitir condutas humanas antes proibidas pela norma decorrente do texto normativo revogado, seja para proibir conduta humana antes permitida pela norma decorrente do texto normativo revogado.

\footnotetext{
AFONSO DA Silva como de eficácia plena e de eficácia contida por fugir ao escopo do presente estudo.

${ }^{33}$ Silva, José Afonso da. Aplicabilidade das normas constitucionais, 7.ed. 2t. São Paulo: Malheiros, 2008, p73-6

34 idem

35 idem
} 
Ademais, e para não deixar de lado a discussão em sede constitucional, às normas constitucionais deve ser dado o maior alcance possível, até mesmo para regular condutas humanas em um determinado sentido, como o de impedir alterações administrativas, exemplo do que faz o $₫ 2^{\circ}$ do art. 242 da Constituição Federal. É o que Canotilho ${ }^{36}$ chama de "princípio da máxima efectividade".

\subsection{Natureza jurídica da revogação}

Perquirir a natureza jurídica da revogação impende esclarecer do que se trata quando se fala em revogação. É dizer: a revogação atinge a existência, a validade ou a eficácia do enunciado prescritivo? Indo além, Moussallem ${ }^{37}$ ressalta que tal estudo deve, também, perquirir se a revogação atingiria também a vigência e a aplicação. Percorrendo as teorias sobre a natureza jurídica da revogação, Moussallem ${ }^{38}$ esclarece que para Eugenio Bulygin a revogação atinge a validade de um determinado enunciado prescritivo. Isso se daria pelo fato de que, em sendo revogado um determinado enunciado prescritivo de um sistema jurídico se estaria, em verdade, inaugurando um novo sistema jurídico, ao qual não mais pertenceria o enunciado prescritivo revogado e, nessa medida, para o qual não mais seria válido.

Esse raciocínio se torna possível, segundo suas lições, pela relação que um determinado enunciado prescritivo teria com o espaço de tempo, é dizer: um determinado sistema jurídico, com seus enunciados prescritivos, seria válido em um determinado

\footnotetext{
${ }^{36}$ Canotilho, J.J. G. Direito Constitucional e teoria da constituição.7.ed. 13.Coimbra: Almedina, 2003 1218

37 Moussallem, Tarek Moyses. Revogação em matéria tributária. São Paulo: Noeses, 2007, p. 192 38 idem

${ }^{39}$ Bulygin, Eugenio. Tiempo e validez. In: ALCHOURRÓN, Carlos E; BULYGIN, Eugenio.
}

espaço de tempo e, nessa medida, em outro espaço de tempo, após o enunciado revogador, seria inválido o enunciado já revogado. Contudo, pelas palavras de Bulygin transcritas por Moussallem, resta claro que, em verdade, a corrente adotada por aquele não é no sentido da invalidade como conseqüência da revogação, mas sim a inexistência como conseqüência da revogação, na medida em que "como conseqüência de sua derrogação a norma deixa de existir no sentido de que já não pertence aos sistemas subseqüentes". ${ }^{39}$ Nesse sentido, verifica-se que são tratados como sinônimos - ao menos para fins de explicar as conseqüências da revogação de um enunciado prescritivo - os termos invalidade e inexistência. Esse raciocínio levaria a um fenômeno inexplicável: a aplicação de determinado enunciado prescritivo inexistente. Explica-se: em se adotando tal posicionamento, seriam possíveis situações fáticas, ainda reguladas pela lei inexistente, porquanto criadas durante a existência do texto anterior, em respeito ao brocado tempus regit actum.

Essa possibilidade (aplicação de determinado enunciado prescritivo inexistente) não é olvidada por Bulygin, que a menciona em seu trabalho, segundo ensina Moussallem $^{40}$. Para afastar tal argumento, Bulygin se posiciona no sentido de que, em momento após o enunciado revogador, o enunciado revogado nunca mais seria o mesmo, mas outro. Explica-se: enquanto antes da revogação o enunciado tinha força plena, após a revogação o enunciado revogado traria outra norma, qual seja, a de que tal enunciado somente se aplicaria às

Análisis Lógico y derecho. Madrid: Centro de Estúdios Constitucionales, 1991, p.210, apud MOUSSALLEM, Tarek Moyses. Revogação em matéria tributária. São Paulo: Noeses, 2007, p. 193 ${ }^{40}$ Moussallem, Tarek Moyses. Revogação em matéria tributária. São Paulo: Noeses, 2007, p. 194 
situações ocorridas em seu espaço de tempo, de maneira que seria norma diferente, porquanto agora de aplicação limitada naquele intervalo temporal. Com isso se torna possível afirmar que a norma revogada, em verdade, não mais existe, na medida em que fora substituída pela nova norma, formada pelo enunciado revogado e pelo enunciado revogador, que limitou temporalmente a aplicação do enunciado revogado. Em que pese concorde que seja uma das teorias mais coerentes, Moussallem destaca problemas não solucionados por ela: (i) como poderia ser aplicado um enunciado prescritivo sem estar válido? (ii) como seria possível a uma norma determinar a aplicação da outra sem que tais fatos estejam em seu intervalo de tempo?

Em continuidade de seu raciocínio, Moussallem lembra a lição de Paulo De Barros Carvalho, para quem, inicialmente, seria o caso de reconhecer a revogação como somente ocorrida após o lapso temporal suficiente para que todas as situações fáticas nascidas sob a égide do texto revogado deixassem de existir. Só então a norma teria o "desaparecimento da validade", mas, em momento posterior, relata Moussallem ${ }^{41}$, mencionando Paulo de Barros Carvalho: "O professor paulista (...) desloca o problema da revogação da validade para a vigência, afirmando que a revogação tem por efeito a retirada da vigência da norma para os casos futuros". Contudo, salienta o retorno do mesmo problema verificado quando da adoção da teoria da inexistência: como aplicar um enunciado prescritivo não mais vigente?

Após desenvolver o raciocínio à luz de Eugenio Bulygin e Paulo de Barros Carvalho, Moussallem propõe a aplicação da teoria dos atos de fala para explicar os diferentes momentos de implementação de um enunciado prescritivo revogador, tomando

\footnotetext{
${ }^{41}$ Moussallem, Tarek Moyses. Revogação em matéria tributária. São Paulo: Noeses, 2007, p. 195
}

por base o conceito de "intervalo de subsunção", expressão que explica a subsunção de determinados fatos a determinados enunciado prescritivos em um determinado lapso temporal. Por tal teoria a fala de um enunciado revogador traria em si vários conteúdos, a saber: (i) retirada de aplicação do enunciado revogado aos atos acontecidos após a incidência do enunciado revogador; (ii) a total perda de validade e vigência do enunciado revogado quando não mais possível sua aplicação aos fatos já exauridos.

A essência jurídica do instituto revogação encontra, como visto, questões de alta indagação, sobre as quais a mais abalizada doutrina se debruça. Nos parece, todavia, que não se trata de: i) retirar a existência de um texto normativo, na medida em que, como bem mencionado por Paulo de Barros Carvalho, ainda podem haver relações jurídicas nascidas sob a égide do texto anterior e por ele devendo ser reguladas; ii) retirar a eficácia de um texto normativo, também pela possibilidade de permanência de relações jurídicas nascidas sob a égide do texto anterior e por ele devendo ser reguladas; iii) retirar a validade de um texto normativo, na medida em que entendemos validade como a relação de pertinência vertical de um determinado texto normativo, sob o prisma de todo o ordenamento jurídico que lhe é superior e, nessa medida, lhe confere suporte de validade.

Ante o exposto, nos resta reconhecer que a revogação de um texto normativo retira a eficácia desse texto para todas as relações intersubjetivas ocorridas após a vigência do enunciado prescritivo revogador. 


\subsection{A Revogação tácita como atividade interpretativa}

Acima afirmamos que, em verdade, não existe revogação tácita. Naquele momento os argumentos se basearam na estrutura lógicoformal do sistema dos enunciados prescritivos, é dizer, a Lei Complementar n. 95/98, cujo artigo $9^{\circ}$ estabeleceu a necessidade de cláusula expressa para revogação, derrogou a Lei de Introdução às Normas do Direito Brasileiro - não, obviamente, por revogação tácita, eis que estamos aqui a defender a inexistência de tal instituto enquanto revogação $\neg-$ por ausência de suporte constitucional, eis que a Constituição Federal de 1988 dispôs, em seu art. 59, parágrafo único, a necessidade de Lei Complementar para dispor sobre o processo legislativo, em complementação às normas constitucionais.

Também é certo que a disposição do parágrafo único do art. 59 não fulminou completamente a LINDB, mas somente aquelas disposições que versam elaboração (e revogação) da lei, eis que ela (LINDB) dispõe mais sobre interpretação do que sobre elaboração, como aduzimos acima. Nesse momento, verificaremos como - e em que medida - a atividade de perquirição acerca da revogação ou não de um texto normativo, de maneira tácita, se enquadra, em verdade, como atividade de interpretação da lei e não atividade de verificação de revogação dela.

Carlos Roberto Gonçalves ${ }^{42}$ ensina que a revogação tácita se dá quando a lei nova "mostra-se incompatível com a lei antiga ou regula inteiramente a matéria", pelo que se depreende ser mais uma questão de antinomia - incompatibilidade - normativa do que de revogação em si. Mais à frente, Gonçalves $^{43}$ pondera que "a revogação

${ }^{42}$ Gonçalves, Carlos Roberto. Direito civil brasileiro. v.1. parte geral. 10.ed. São Paulo: Saraiva, 2012, p. 66

43 idem expressa é a mais segura, pois evita dúvidas e obscuridades", deixando claro que a aceitação, em um caso concreto, da revogação tácita depende do interprete, lembrando que "na impossibilidade de coexistirem normas contraditórias, aplica-se o critério da prevalência da mais recente".

Ora! Prevalecer significa ter mais valor, predominar. Nessa medida, reconhecer que a lei nova tem mais valor, predomina, implica, por pressuposto, reconhecer que a lei antiga - que tem menos valor - tem valor, ou seja, está, ainda, válida. Com isso, inegável reconhecer a ainda validade, vigência e eficácia daquela lei que, episodicamente, fora afastada pela aplicação do critério cronológico ou da especialidade.

Tomemos o exemplo dado por Gonçalves" ${ }^{44}$ " Com a entrada em vigor, por exemplo, do Código de Defesa do Consumidor, deixaram de ser aplicadas às relações de consumo as normas de natureza privada estabelecidas no Código Civil de 1916 e em leis esparsas que tratavam dessa matéria". Nesse exemplo fica clara a não revogação do Código Civil pelo advento do Código de Defesa do Consumidor, mas sim o afastamento episódico daquele diploma normativo, é dizer, as disposições do Código Civil não mais seriam aplicadas às relações consumeristas, permanecendo, todavia, hígido o Código Civil para todas as relações intersubjetivas que não se enquadravam em relações de consumo, ressalte-se, de muito maior frequência empírica do que estas.

Em outro exemplo, também oriundo do direito civil, Maria Helena Diniz, quando cuida do direito sucessório decorrente da união estável, notadamente à existência de direito real de habitação ao companheiro sobrevivente, aduz que "pelo Código Civil, tal

\footnotetext{
${ }^{44}$ Gonçalves, Carlos Roberto. Direito civil brasileiro. v.1. parte geral. 10.ed. São Paulo: Saraiva, 2012, p. 66 Importante ressaltar que esse exemplo é dado pelo autor justamente quando trata do tema "revogação tácita".
} 
direito só é deferido ao cônjuge sobrevivente; mas, por ser norma especial, o art. $7^{\circ}$ da lei acima referida está vigente e pode ser aplicado ao companheiro supérstite", (estava valando da Lei n. 9278/96) momento em que ressalva:

Sem embargo dessa nossa opinião, há quem ache, como Mário Luiz Delgado e Zeno Veloso, que ante o silencio eloqüente (beredtes Schweigen) do Código Civil a respeito, houve intentio de excluir o direito real de habitação do convivente, logo não há lacuna a ser preenchida

Esta gama de opiniões doutrinárias em sentido contrário - que acaba por desencadear divergências jurisprudenciais ${ }^{45}$ sobreleva a necessidade de maior clareza, por parte do legislador, no sentido de revogar expressamente textos normativos quando essa for sua intenção. Seguindo o raciocínio, na questão acerca da existência do direito real de habitação no caso de falecimento de um dos companheiros, Maria Helena Diniz salienta ser caso de "antinomia de segundo grau, ou seja, um conflito entre norma anterior especial (Lei n. 9278) e norma posterior geral (CC 1831), que, por sua vez, gera antinomia entre o critério da especialidade e o cronológico", ou seja, tratase de antinomia normativa, devendo ser solucionada pelos critérios hermenêuticos destinados a tanto, e não hipótese de revogação.

Como visto, a revogação tácita se funda na incompatibilidade de lei nova em relação à lei anterior, nos casos em que a lei nova: (i) seja incompatível com a lei anterior; e/ou (ii) regule completamente a matéria. Essa circunstância cria, respectivamente, dois

\footnotetext{
${ }^{45}$ Ressalte-se excelente pesquisa jurisprudencial realizada e colacionada na obra de Maria Helena Diniz (Curso de direito civil brasileiro. v.5. direito de família. 27.ed. São Paulo: Saraiva, 2012) 46 Tartuce, Flávio. Direito civil. v.5: direito de família. 8.ed. Rio de Janeiro: Forense, 2013, p. 266
}

problemas de ordem interpretativa: (i) determinar quando a lei nova é incompatível com a anterior, de maneira a não permitir a aplicação simultânea; e (ii) estabelecer quando a lei nova regulou totalmente a matéria, de maneira a afastar, por completo, a lei anterior. Exemplo patente é a situação, verificada no direito civil, do companheiro, tanto em relação ao direito de família, quanto no que diz respeito aos direitos sucessórios, em que a própria doutrina se debate para chegar à conclusão da revogação, ou não, da Lei n. 8971/94 pela Lei n. 9278/96 ou até mesmo de ambas as Leis pelo Código Civil de 2002.

Flávio Tartuce ${ }^{46}$ ressalta que Álvaro Vilaça Azevedo entende que a Lei n. 9278/96 "não revogou totalmente a primeira, havendo, no passado, uma aplicação concomitante das normas, uma colcha de retalhos legislativa". A expressão não poderia ser melhor para explicitar o que a admissão de revogação tácita ocasiona no sistema: uma colcha de retalhos legislativa. Muito melhor seria se os dispositivos legais, em atendimento do que de há muito propugnava Carlos Maxmimiliano e previsto desde 1998 pela LC 95, trouxessem cláusula de revogação expressa.

Carlos Roberto Gonçalves ${ }^{47}$ em sentido oposto, defende a revogação das leis anteriores pelo Código Civil: "restaram revogadas as mencionadas Leis n. 8.971/94 e 9.278/96 em face da inclusão da matéria no âmbito do Código Civil de 2.002”.

Maria Helena Diniz ${ }^{48}$, quando enumera os efeitos jurídicos da união estável, pontua o direito a alimentos, momento em que menciona as Leis n. 8.971/94 e 9.278/96, pelo que se depreende ser seu entendimento

\footnotetext{
${ }^{47}$ Gonçalves, C. R. Direito civil brasileiro. v.6. direito de família. 9.ed. São Paulo: Saraiva, 2012, p. 608

${ }^{48}$ Diniz, M. H. Curso de direito civil brasileiro. v.5. direito de família. 27.ed. São Paulo: Saraiva, 2012, p. 454.
} 
pela não revogação destas pelo Código Civil de 2002. Falando da Lei n. 8.971/94 Silvio Venosa $^{49}$ expõe o problema: “a primeira dúvida que aflora com relação a essa lei é a permanência de sua vigência, tendo em vista a promulgação da lei n. 9.278 de 10-5-96." Criticando o laconismo do legislador quanto à tomada de posição em relação à revogação Venosa pontua que "o legislador poderia ter poupado o intérprete, mas não o fez". E segue Venosa ${ }^{50}$ : "era de se aguardar que o Código Civil de 2.002, ao disciplinar a união estável, resolvesse essas questões, pois, em princípio, derroga as leis anteriores sobre a matéria".

Para Maximiliano 51 "a incompatibilidade implícita entre duas expressões de direito não se presume". Não se presumindo, tem de ser provada a incompatibilidade. Essa prova se dá de duas maneiras: i) texto de lei revogação expressa; ou ii) atividade do intérprete do direito, quando da aplicação. Maximiliano ressalta, nesse caso, que a prova da incompatibilidade se dará com a existência de "argumentos sólidos". A construção é clara: se a revogação tem de ser demonstrada por argumentos sólidos, estamos no campo da argumentação e não no campo da revogação de texto normativo. Em se tratando do campo da argumentação, que se dá na seara da interpretação e aplicação dos textos normativos, não se pode falar em revogação, mas de atividade interpretativa destinada à solução de antinomia.

Quando, em havendo antinomia, o intérprete/aplicador do direito se vale de critérios para a solução, não há dúvidas que se encontra no campo da

\footnotetext{
${ }^{49}$ Venosa, Silvio de Salvo. Direito civil. v.6. direito de família. 13.ed. São Paulo: Atlas, 2013, p. 47

${ }^{50}$ Venosa, Silvio de Salvo. Direito civil. v.6. direito de família. 13.ed. São Paulo: Atlas, 2013, p. 50

51 Maximiliano, Carlos. Hermeneutica e aplicação do direito. 18.ed. Rio de Janeiro: Forense, 2000, p. 358
}

interpretação/aplicação, sem que tal atividade redunde em revogação do texto normativo não aplicado para aquele caso concreto, eis que plenamente possível aplicar em outro, na medida em que seja mais adequado e os valores imanentes ao outro caso ensejem a aplicação do outro enunciado prescritivo. Em apertada síntese, é isso que pondera Karl Larenz ${ }^{52}$ quando fala da "ponderação de bens no caso concreto". Menciona Larenz que "em caso de conflito se se quer que a paz jurídica se restabeleça, um ou outro direto (ou um dos bens jurídicos em causa) tem que ceder até certo ponto perante o outro ou cada um entre si". O mesmo sentido - verificar a prevalência somente em caso concreto - é seguido por Konrad Hesse ${ }^{53}$, quando afirma que "onde nascem colizões (sic) não deve, em 'ponderação de bens' precipitada ou até 'ponderação de valor' abstrata um ser realizado à custa do outro".

\subsection{Revogação do texto de lei}

Pelo que se pôde estudar a respeito do fenômeno jurídico revogação, se está diante de algo imanente ao texto de lei (aqui também chamado de texto normativo ou enunciado prescritivo), o que, entendemos, somente pode ocorrer de maneira expressa, eis que a revogação tácita, seja pelo fundamento lógico-formal (inconstitucionalidade $\mathrm{da}$ LINDB quando assim dispõe), seja pelo fundamento argumentativo até aqui expendido, não é revogação, mas sim atividade interpretativa destinada à solução de antinomias, sem que possa redundar em revogação de um texto anterior.

\footnotetext{
52 Larenz, Karl. Metodologia da ciência do direito. 6.ed. [tradução de José Lamego] Lisboa: Fundação Calouste Gulbenkian, 2012, p. 575

53 Hesse, Konrad. Elementos de direito constitucional da república federal da Alemanha [tradução da (20a edição alemã) de Dr. Luís Afonso Heck]. Porto Alegre; Sergio Antonio Fabris Editor, 1998, p. 66
} 


\subsection{Revogação da "Norma Jurídica em sentido estrito"}

Mais problemática - caso se entenda que existe - é a revogação da "norma jurídica em sentido estrito" para usar as palavras de Paulo de Barros Carvalho, ou simplesmente "norma jurídica”, como descrita por Eros Grau, ou seja, o comando normativo decorrente da interpretação/aplicação do texto normativo.

Essa revogação - aqui entendida como retirada de eficácia de determinada norma jurídica - decorrerá da evolução do pensamento da doutrina e jurisprudência jurídicas a respeito do alcance de determinado texto normativo. Exemplo de tal revogação ocorreu, durante muitos anos, na seara penal, com a interpretação da expressão "mulher honesta", prevista no tipo penal "posse sexual mediante fraude", estampada na redação original do art. 215 do Código Penal. Certamente, quando da elaboração do texto do Código Penal, na década de 1930, o legislador quis se referir à mulher que não tinha experimentado relações sexuais, o que não mais se coadunava, de há muito, ao conceito de honestidade quando da revogação expressa do termo, por ocasião da Lei n. 11.106/05, consoante nos relata Damasio Evangelista de Jesus ${ }^{54}$, quando esclarece ser mulher honesta: "a que se conduz dentro dos padrões aceitos pela sociedade onde vive", restando claro não mais se relacionar à relação de virgindade, tanto que, quanto à virgindade, Damasio esclarece: "não é exigida pelo tipo".

Com isso, verifica-se um exemplo de revogação de norma jurídica no sentido aqui utilizado, conquanto não se tem aplicação de um texto normativo com o mesmo significado do momento de sua elaboração. Para usar o exemplo acima mencionado temos: i) norma jurídica quando da elaboração do código penal: é crime "ter conjunção carnal com mulher virgem, mediante fraude"; ii) norma jurídica após décadas de evolução da sociedade e, em conseqüência, da doutrina e jurisprudência penais: é crime "ter conjunção carnal com mulher que se comporta segundo padrões moralmente aceitos pela sociedade, não necessariamente virgem". Assim, pode-se afirmar que a evolução da interpretação/aplicação dos textos normativos é atividade que provoca a revogação de norma jurídica se a entendermos como o produto da interpretação do texto normativo. Não se confunda tal afirmação com a aquiescência à revogação tácita. As diferenças são claras: texto normativo somente se revoga com texto normativo que expressamente se dirija a esse fim. Norma jurídica decorrente da interpretação de texto normativo pode ser revogada por mudança na interpretação desse mesmo texto normativo.

\section{Considerações Finais}

A par de toda a construção - e discussão - doutrinária acerca da revogação, entendemos que o instituto jurídico pode ser abordado sob dois prismas.

O primeiro prisma é a revogação do texto normativo. Em tal segmento, a revogação somente se dá pela via expressa, vale dizer, pela enunciação, por meio de um enunciado revogador, de que tal texto anterior está revogado - o que é chamado pela doutrina de revogação expressa. Isso se dá, basicamente por duas constatações: i) a LC95/98, por expresso mandamento constitucional, nos termos do parágrafo único do art. 59, tornou sem efeito a disposição do art. $2^{\circ} \$ 1^{\circ}$ da LINDB que

54 Jesus, Damásio Evangelista de. Código penal

anotado. 7.ed. São Paulo: Saraiva, 1997. p. 668-9 
dispõe acerca da revogação "quando seja incompatível ou quando regule inteiramente a matéria de que tratava a lei anterior"; ii) a atividade de aferição de se, quando e em que medida lei posterior é incompatível ou regula inteiramente a matéria de que tratava a lei anterior é atividade interpretativa, e deve ser alocada no campo da interpretação dos textos normativos, destinada à solução de antinomia, não o campo da revogação. Não entendemos que a solução de antinomia, de per si, possa resultar em revogação, na medida em que, no mais das vezes - se não em todas - resulta no afastamento episódico da aplicação daquele texto normativo para aquela situação in concreto não significando, todavia, a impossibilidade de aplicação daquele texto, momentaneamente afastado, para outra situação fática.

O segundo prisma sob o qual pode ser observado o fenômeno da revogação é o da revogação das normas jurídicas entendidas como produto decorrente da interpretação/aplicação do texto normativo. Nesse aspecto, a revogação está como evolução do próprio ordenamento jurídico, cientificamente estruturada e fundamentadamente aplicada. Nesse campo, talvez, melhor se insira aquilo que se costuma chamar de revogação tácita. Em se admitindo que essa modalidade de revogação - tácita exista, não se estaria diante de instituto voltado à revogação de textos normativos, porquanto atividade somente possível pela via da revogação expressa, mas apenas e tão somente revogação como evolução do próprio ordenamento jurídico, composto por normas que, por sua vez, são produto da interpretação/aplicação dos textos normativos (também chamados de enunciados prescritivos).

Por outro lado, em se entendendo revogação como instituto apenas destinado ao texto normativo, a revogação seria instituto voltado somente aos textos normativos e não às normas jurídicas, porquanto aqueles diferem destas. A revogação de texto normativo não impõe sua inexistência ou invalidade, mas apenas sua ineficácia para relações jurídicas nascidas após a vigência do enunciado prescritivo revogador.

O enunciado prescritivo revogador, após entrar em vigor e, imediatamente, retirar a eficácia do enunciado prescritivo revogado, não perde a validade ou a existência, mas apenas tem o exaurimento de seus efeitos, de maneira que permanece latente no sistema jurídico, conservando o novo ordenamento jurídico inaugurado pelo efeito revogador que trouxe.

\section{Bibliografia}

1. CANOtilho, J.J. Gomes. Direito Constitucional e teoria da constituição. 7.ed. 13.reimp. Coimbra: Almedina, 2003.

2. CARVALHO, Aurora Tomazini. Teoria geral do direito: (o constructivismo logicosemântico). Tese. Doutorado em Direito. São Paulo: Pontifícia Universidade Católica, 2009. Disponível em http://www.sapientia. pucsp.br/tde_busca/arquivo.php?codArquiv $\mathrm{o}=9427$ acesso em 27/06/2014.

3. CARVAlHO, Paulo de Barros. Direito Tributário, Linguagem e Método. São Paulo: Noeses, 2013.

4. DINIZ, Maria Helena, Lei de introdução ao código civil brasileiro interpretada. 7.ed. São Paulo: Saraiva, 2001.

5. Curso de direito civil brasileiro. v.1., teoria geral do direito civil, 28.ed. São Paulo: Saraiva, 2011. 
6. Curso de direito civil brasileiro. v.5. direito de família. 27.ed. São Paulo: Saraiva, 2012.

7. FERRAZ JUNIOR, Tercio Sampaio. Introdução ao estudo do direito - técnica, decisão, dominação. São Paulo: Atlas, 1988.

8. GONÇALVES, Carlos Roberto. Direito civil brasileiro. v.1. parte geral. 10.ed. São Paulo: Saraiva, 2012. 9. GONÇALVES, Carlos Roberto.

Direito civil brasileiro. v.6. direito de família. 9.ed. São Paulo: Saraiva, 2012.

10. GRAU, Eros Roberto. O direito posto e o direito pressuposto. 6.ed. São Paulo: Malheiros, 2005.

11. . Ensaio e discurso sobre a interpretação/aplicação do direito. 5.ed. São Paulo: Malheiros, 2009.

12. HESSE, Konrad. Elementos de direito constitucional da república federal da Alemanha [tradução da (20ª edição alemã) de Dr. Luís Afonso Heck]. Porto Alegre; Sergio Antonio Fabris Editor, 1998.

13. JESUS, Damásio Evangelista de. Código penal anotado. 7.ed. São Paulo: Saraiva, 1997. KELSEN, Hans. Teoria pura do direito. [trad. João Baptista Machado] 6.ed. São Paulo: Martins Fontes, 1998.

14. LARENZ, Karl. Metodologia da ciência do direito. 6.ed. [tradução de José Lamego]
Lisboa: Fundação Calouste Gulbenkian, 2012.

15. MAXIMILIANO, Carlos. Hermenêutica e aplicação do direito. 18.ed. Rio de Janeiro: Forense, 2000.

16. MONTORO, André Franco. Introdução à ciência do direito. 25.ed., São Paulo: Revista dos Tribunais, 1999.

17. MOUSSALLEM, Tarek Moyses. Revogação em matéria tributária. São Paulo: Noeses, 2007.

18. RÁO, Vicente. O direito e a vida dos direitos. 5.ed. anotada e atualizada por Ovídio Rocha Barros Sandoval, São Paulo: RT, 1999. 19. REALE, Miguel. Lições preliminares de direito. 25.ed., São Paulo: Saraiva, 2000.

20. SCHMILL, Ulisses. La derogación y la anulación como modalidades del âmbito temporal de validez de lãs normas jurídicas. (texto anexo)

21. DA SILVA, José Afonso. Aplicabilidade das normas constitucionais, 7.ed. 2t. São Paulo: Malheiros, 2008,

22. TARTUCE, Flávio. Direito civil. v.5: direito de família. 8.ed. Rio de Janeiro: Forense, 2013.

23. VENOSA, Silvio de Salvo. Direito civil. v.6. direito de família. 13.ed. São Paulo: Atlas, 2013. 